\title{
Religião, morte e políticas públicas de saúde: cientistas das religiões na elaboração dos processos de luto.
}

\author{
Clarissa De Franco ${ }^{1}$ \\ Valéria Rocha Torres ${ }^{2}$
}

\section{RESUMO}

O presente artigo tem por objetivo refletir a respeito da Ciência das Religiões aplicada e sua interlocução com políticas públicas de saúde voltadas ao enfrentamento da morte e de seus desdobramentos ou facetas, como luto, cuidados paliativos... Partimos do pressuposto que o|a cientista da religião no Brasil tem uma atuação ainda muito restrita nas equipes multidisciplinares que atuam com a temática da morte, e nossa comunicação busca demarcar a importância deste|a profissional para lidar com a morte, especialmente no que se refere ao manejo dos conteúdos simbólicos e religiosos, que atravessam o campo da saúde e das políticas públicas. Nosso artigo demonstra, em consonância com outros autores e autoras da área, que há um despreparo generalizado entre profissionais da saúde para lidar com a morte, e entendemos que esta lacuna pode ser parcialmente preenchida por profissionais que atuam com as religiões, entendendo a importância do papel das religiões e espiritualidades na questão da morte. Para tal tarefa, apresentamos algumas transformações de concepções sobre a morte do SUS, da OMS, que incluem a espiritualidade como um campo fundamental dos processos de saúde, especialmente os que envolvem a finitude.

Palavras-chave: luto; morte; religião; saúde pública.

1 Psicóloga, doutora e mestra em Ciência das Religiões, com Pós-Doutorado em Ciências Humanas e Sociais. É Pesquisadora Doutora Colaboradora da Universidade Federal do ABC. E-mail: clarissadefranco@hotmail.com.

2 Historiadora, mestre em Historia Social pela Unicamp, doutoranda em Ciência da Religião PUC-SP, valeriarochatorres@gmail.com. http://lattes.cnpq.br/2424289174543890. 


\title{
RELIGION, DEATH AND PUBLIC HEALTH POLICIES: SCIEN- TISTS OF RELIGIONS IN THE ELABORATION OF GRIEVING PROCESSES.
}

\begin{abstract}
This article aims to reflect on the Science of Religions applied and its interlocution with public health policies aimed at coping with death and its unfolding or facets, such as mourning, palliative care ... We assume that the scientist of religion in Brazil has a still very limited role in multidisciplinary teams that work on death, and our communication seeks to demarcate the importance of this professional to deal with death, especially with regard to the management of symbolic and religious contents, which cross the field of health and public policy. Our article demonstrates, in agreement with other authors and authors of the area, that there is a generalized lack of preparation among health professionals to deal with death, and we understand that this gap can be partially filled by professionals who work with religions, understanding the importance of role of religions and spiritualities in the question of death. For this task, we present some transformations of conceptions about the death of SUS, WHO, which include spirituality as a fundamental field of health processes, especially those involving finiteness.
\end{abstract}

Keywords: mourning; death; religion; public health

\section{Introdução}

Partimos da preocupação de duas estudiosas das religiões, com perspectivas particulares de áreas clássicas (Psicologia e História), que se encontraram diante do interesse por um tema central na Ciência das Religiões e também na Saúde: a morte. Não por acaso, o encontro destas perspectivas dá-se no palco da disciplina aplicada e da perspectiva de atuação profissional dos/as cientistas das religiões na composição de equipes multidisciplinares que atendem pessoas em enfretamento da morte (vivenciando luto ou que estão sob a assistência dos Cuidados Paliativos).

Tanto a formação dos profissionais da área da saúde quanto os Cuidados Paliativos são duas demandas importantes para formulação de políticas públicas no que diz respeito à humanização dos cuidados com pacientes e suas famílias que enfrentam a finitude da vida. Assim, este 
artigo é o resultado da revisão de literatura que articula produções específicas da área da saúde pública que refletem a preocupação tanto com formação profissional da saúde e o seu despreparo para o enfretamento da morte, quanto com a ampliação das equipes multidisciplinares que atuam especificamente em instituições de Cuidados Paliativos e da contribuição da inserção dos|as cientistas das religiões nesses espaços profissionais.

A partir desta revisão de literatura, procuramos alinhar a possibilidade da atuação dos (as) cientistas das religiões como participante destas equipes de trabalho abordando inicialmente a perspectiva que trata especificamente da importância histórica das religiões/ sistemas de crenças na formulação do enfrentamento finitude da vida ao longo da história do Brasil, principalmente no que concerne a ideia e a prática do "bem morrer", que atualmente é retomado por alguns seguimentos da saúde pública como forma de crítica em ao modelo de gestão da morte que se estruturou no país durante todo o século XX, considerado "desumano, frio excessivamente racionalizado e institucionalizado" (MENEZES e BARBOSA, 2013). Nesse sentido, procuraremos demonstrar que o processo do "bem morrer" que inclui historicamente a elaboração do luto, tem seu fundamento nas complexas experiências religiosas e sistemas de crenças que forjaram a sociedade brasileira desde o período colonial.

Além disso, trazemos a revisão de literatura que indica as demandas da saúde pública em relação à assistência de pacientes considerados "sem possibilidade terapêutica de cura", a maioria desses artigos se encontram na Revista Ciência \& Saúde que dedicou uma edição especial para tratar do profissional da saúde diante da morte e do luto como um aspecto fundamental dos protocolos biomédicos tanto quanto são os cuidados necessários à preservação da saúde, como aponta a editora chefe da Revista Maria Cecília de Souza Minayo.

Por que é importante que a saúde coletiva assuma este tema? Porque ele trata da realidade mais insofismável do ser humano. Portanto, morrer com dignidade, assistido corretamente em todas as instâncias do SUS é tão importante como receber os cuidados necessários para preservar a saúde e prosseguir na jornada sempre finita e provisória. Frequentemente, profissionais altamente especializados e competentes falham na hora de dar uma "noticia difícil" a um paciente e dele se distanciam quando já não é possível "salvá-lo". É claro que para todos, é muito doloroso 
pressentir e presenciar a morte. Mas é mais difícil para a racionalidade médica - que influencia todas as carreiras das ciências da vida - pautada numa certa visão de que a morte seria o fracasso de sua habilidade na solução de problemas. Questionando essa racionalidade, os artigos aqui apresentados falam da ética, da comunicação, da sensibilidade no modo de agir de quem está vivo e tem como profissão conduzir o sopro da existência até que ela se apague : esse processo e esse tempo que precisam ser pensados, respeitados e vividos com dignidade! ( MINAOY, 2013, p.2484)

Os artigos da área da saúde tratam de duas questões fundamentais para o processo de elaboração de políticas públicas de enfrentamento da morte e do luto: a primeira é a falta de educação para a morte como uma falha do perfil socioprofissional dos que atuam na área da saúde. A segunda se constitui num desdobramento da primeira e diz respeito aos reflexos diretos deste despreparo no cotidiano de enfrentamento da morte no universo da saúde coletiva e individual, as temática arroladas pelos artigos são: o cuidado com idosos em idade avançada que em tese estão mais próximos da morte; cuidados com crianças e adultos diagnosticados como 'fora das possibilidades terapêuticas de cura' e quais os procedimentos tomados a partir deste diagnóstico; narram as práticas dos cuidados paliativos e sua vinculação com o ideário do "bem morrer".

Por meio das questões relacionadas pelos profissionais de saúde na revisão de literatura da primeira parte do artigo, percebemos a ausência especifica do significado que as religiões/ sistemas de crenças representam na construção social-cultural-psicológica do enfrentamento da morte, por isso, abordamos a presença o pluriculturalismo religioso no Brasil e sua profunda influência na produção do ideário de bem morrer e da boa morte na sociedade brasileira a partir do século XVII, esta tradição pode ser considerada um elemento fundamental do que podemos denominar como ethos religioso brasileiro, sendo assim, não é possível desconsiderá-lo como um dado irrelevante para pensarmos a respeito da humanização da morte como política pública no país.

Na última seção deste artigo, apresentamos as possibilidades de atuação dos (as) cientistas das religiões como integrantes dessas equipes multidisciplinares que formam e ao mesmo tempo formulam políticas públicas em saúde, pois, podemos observar que as questões religiosas 
quando são levadas em consideração por estes autores que se debruçam sobre a temática, são sempre colocadas em suspeita devido ao proselitismo religioso que um(a) líder religioso poderia trazer ao compor tais equipes.

Por este motivo, indicamos que os (as) cientistas das religiões por terem formação interdisciplinar que dialoga com a história, a sociologia, a psicologia e a antropologia, portanto, formação plural e laica, dispõem do perfil adequado para desempenhar esta função trazendo para o campo do enfrentamento da morte e do luto um repertório de conhecimento que produziu e produz o ethos religioso de nossa sociedade. Não se pode apagar o fato de que durante séculos as religiões e religiosidades brasileiras normatizaram os procedimentos individuais e coletivos diante da morte e do luto e que ainda normatizam, pois o Brasil é um país intrinsecamente forjado em experiências religiosas, assim partindo da perspectiva que todos os artigos dos profissionais de saúde indicam que a morte deve ser vista além das questões biológicas e ser pensada como a partir das relações coletivas, é preciso assumir que a morte no Brasil é histórica e fundamentalmente um problema de ordem religiosa.

\section{As demandas da saúde coletiva diante da morte e do luto}

As ciências médicas no Brasil foram assumindo a gestão da morte durante o século XIX, até então, do ponto vista institucional esta gestão competia a Igreja Católica, mais especificamente a enorme rede de Irmandades Religiosas ${ }^{3}$ que se constituíram no país entre os séculos XVII, XVIII e XIX. Assim sendo, foram as Irmandades Religiosas que se incumbiam da assistência ao moribundo e a sua família antes e pós-morte, obviamente não podemos esquecer que o complexo de saúde pública no Brasil, também foi instituído pela Igreja Católica por meio das Santas Casas de Misericórdia. No entanto, a partir de meados do século XIX ocorreu uma inflexão na estrutura da sociedade brasileira com o enriquecimento do país por meio da cafeicultura, com o advento da estrada de ferro e o processo de urbanização, principalmente no Sudeste.

3 Sobral,LucianaO.daGama.Amortecomoescola:apedagogiadebemmorrernaCidadedaBahia (ca. 1640-1759). Faculdade de Filosofia e Ciências Humanas, Universidade Federal da Bahia, Salvador, 2014.203 f.:il. 
Quando a cafeicultura foi tornando-se o principal produto da economia gerador de riqueza no país um novo modelo de sociedade passou a ser forjado a partir desta riqueza, assim, aos nos referimos ao café temos que levar em consideração que estamos analisando um produto que transformou profundamente a História do Brasil e construiu uma civilização em torno deste, não é possível aborda-lo somente em relação ao comércio e produção, temos que contextualizá-lo também do ponto de vista, político e social, pois, foram os fazendeiros de café que politicamente começaram a cunhar o projeto de modernidade no país. A historiografia brasileira sempre que analisa a postura dos cafeicultores do Oeste Paulista os descreve como empreendedores cuja mentalidade burguesa permitiu que o capital acumulado com o café fosse investido e reinvestido em outros setores da economia como indústria, meios de transporte e saúde.

O projeto político de modernidade surge me torno desta demanda, tudo se tornou superlativo, os meios de transporte deveriam ser rápidos, as cidades urbanizadas e higienizadas, a mão de obra livre, o passado colonial apagado, retirado das instituições, superado pelos caminhos do progresso e de uma nova civilização. Neste contexto, começam a se desenhar na mentalidade social política brasileira a ideia de um país mais afinado com os modelos de sociedade europeia (principalmente a sociedade francesa). Tal modelo era formulado em torno do "cidadão ilustrado" e da sociedade livre das amarras e da mentalidade religiosa, considerada como símbolo de atraso e superstição. Esse projeto se fortalece na segunda metade do século XIX no início do apogeu da produção cafeeira, mas há indícios que desde a independência em 1822 começa o enfretamento entre a ciência médica como representante de um projeto de modernidade e as práticas religiosas principalmente no que concerne ao controle sobre processo do morrer.

Esse enfrentamento político entre práticas religiosas e o discurso médico no Brasil começou por meio da produção de uma série de teses médicas condenatórias dos enterramentos nas Igrejas, entre elas destacamos as teses de José Correia Picanço e Manoel Maurício Rebouças (REIS,1991,p.255), este último, ao condenar os sepultamentos nas igrejas, elabora uma série de acusações, inclusive citando casos de "pessoas que entraram em Igrejas - aspiraram o ar fétido emanado 
pelos miasmas da morte - e faleceram“ (Apud REIS, 1991, p. 255). Manuel Rebouças, entre outros médicos, inaugura uma cruzada contra a Igreja Católica e as práticas funerárias ligadas ao catolicismo, essa cruzada atravessa o século XIX, se consolida na segunda metade do mesmo século e teve seu projeto político coroado com a proclamação da República em 1889 que se assentou seu projeto de Estado no saber científico como força política.

Para Margarida Neves, a Primeira República brasileira parece ser um período fértil, para evidenciar aquela dupla tendência de atrair para esfera do Estado os 'homens de scencia' e o fazer científico, e de legitimar por meio da ciência a ação do Estado. (2010, p.42) Complementando Simone Krioff ressalta que, desde o final do século XIX , intensificava-se a crença de que o Brasil, guiado pela ciência, ingressaria em um novo tempo e se tornaria uma nação civilizada. (LOPES,2010, p.50).

O conflito em torno da morte envolvia duas forças - discurso médico e religioso - ambas disputavam o controle das ações do Estado. O discurso médico se apresentava por meio do projeto político liberal que, entre outras bandeiras, atacava a Igreja e as práticas religiosas cotidianas, fundamentalmente as que se vinculavam à morte e ao morrer, como símbolos de atraso e superstição. Por isso, é necessário enfatizar que este conflito que atravessa o século XIX e que teve como epicentro o controle sobre a morte, deixou marcas indeléveis na sociedade brasileira tanto no processo de gradativa medicalização do morrer quanto no processo de esvaziamento de seu sentido religioso. Este embate de ideias, práticas, conceitos, imagens e representações perpassam e informam o imaginário social brasileiro, pois envolve uma questão crucial que é o poder sobre o conhecimento da morte e do sentido de morrer, assim, as marcas indeléveis desse embate político promoveram o gradativo afastamento da morte do convívio social.

Com o advento da República no final do século XIX o modelo médico- cientifico de gestão da morte passa dominar o cenário social brasileiro e temos a consolidação deste modelo durante até meados da segunda metade do século XX, por meio de um processo de excesso de medicalização da morte ( MENEZES, 2014, p.10). No entanto, a partir da década de 1970 a ciências da saúde passaram a discutir esse excesso 
de medicalização da morte, a refletir sobre seus próprios protocolos e avaliar inúmeras dimensões de seu papel diante dos moribundos, dos idosos e das famílias das pessoas "fora de possibilidade terapêutica de cura".

Dessa maneira, trazemos em forma de revisão de literatura publicações da área da saúde que trazem essas questões à tona e tratam de indicar a importância cada vez mais presente de humanização no processo da morte e do morrer, compreendendo a morte como uma questão social e coletiva que envolve os profissionais da saúde, os pacientes, suas famílias e fundamentalmente a maneira como todos os envolvidos representam e significam o processo do morrer e do luto.

A revista Ciência \& Saúde no ano de 2013 dedicou uma edição especial à morte e ao luto, como já citado anteriormente. O editorial da revista assinala a preocupação em relação à escassa produção acadêmica na área da saúde a respeito da morte e do luto por isso a ideia de organizar um número temático com o eixo em "Finitude, Morte e Luto", assim trazemos alguns artigos publicados neste número como uma amostragem do estado da arte em torno da temática e mais que isso os artigos demonstram quais são os fios condutores que ordenam as reflexões entre os profissionais de saúde acerca do enfretamento da morte e do luto no Brasil contemporâneo.

Os pesquisadores do Núcleo de Estudos do Envelhecimento (UFMG/ FIOCRUZ) Karla Giacomin, Wagner Jorge dos Santos e Josélia Oliveira de Araújo Firmo trazem o artigo: "O luto antecipado diante da consciência da finitude: a vida entre os medos de não dar conta, de dar trabalho e de morrer" um estudo etnográfico observacional realizado com 57 idosos assistido pela Estratégia Saúde da Família na zona urbana de Bambuí ( MG) uma cidade do centro-oeste mineiro que fica a $270 \mathrm{~km}$ de Belo Horizonte, este município é conhecido por ter sido objeto de um importante estudo a repeito da moléstia tripanossomíase ( Doença de Chagas), de acordo com os autores um terço da população da cidade se encontra em estado de pobreza e similarmente ao que ocorre no restante do Brasil a população de Bambuí passa por um processo de envelhecimento.

A preocupação central da pesquisa foi, por meio de entrevistas semiestruturadas com esses idosos, desvendar suas principais inquieta- 
ções em relação à ideia de finitude da vida que em tese se aproxima das pessoas com idade mais avançada, a analise dos dados foram orientadas pelos modelos - signos, significados e ações - possibilitaram a emergência de categorias que expressam essas inquietações, como: experiência da morte em vida; experiências dos idosos na atenção à saúde; consciência da finitude e lutos antecipados que tiram o sentido da vida.

Importante compreender que tudo o que for efetivamente dito, insinuado ou mal esclarecido será interpretado: as pessoas e famílias escutam por meio de filtros históricos, culturais, étnicos muito diferentes. Logo, a experiência da doença não pode ser considerada um simples reflexo do processo patológico no sentido biomédico do termo; e sim uma construção cultural expressa em 'maneiras específicas de pensar e agir'. O saber profano dos entrevistados obedece à sua visão do mundo para dizer dos sofrimentos ou surpresas que o corpo revela, mas a medicina ' não escuta deste ouvido, pois participa de uma cultura sábia, própria para um grupo restrito. (GIACOMIN et al. pp. 2491-2492)

No relato das entrevistas é unanime a conclusão de que o aproximar da finitude da vida traz a marcante sensação de perda - por isso os autores denominam esse processo de luto antecipado - porém, essa sensação de perda não se restringe a perda de pessoas queridas, mas uma perda mais profunda que diz respeito aos controles do próprio corpo e é em função deste quadro que, obviamente, os idosos procuram o sistema de saúde, de acordo com os autores "os idosos procuram os serviços na esperança de minimizar sofrimentos próprios e alheios, sejam eles de fundo moral, espiritual, físico, psicológico e ou funcional" (Ibidem, p. 2492).

No entanto, as respostas do saber médico com a qual essas pessoas se deparam e, de acordo com os autores assimilam, é que o processo velhice-doença-incapacidade é implacável, não há nada o que se fazer diante deste fato da vida a não ser a aceitação resignada, a análise dos autores acerca deste quadro relacional entre profissional de saúde e pacientes traz a tona duas importantes demandas: os limites do conceito cuidado integral proposto pelas políticas de saúde e o despreparo das equipes para lidar com a finitude humana, seja na vida ou na morte.

Um pouco mais específico em relação à formação dos profissionais da área de saúde no que diz respeito ao enfrentamento da morte e do 
luto o artigo "Morte e Luto: A importância da Educação para o Profissional de Saúde" de Janaína Luiza dos Santos et al (2014) publicado na Revista Ciência e Saúde da UNIPAR aborda as deficiências na estrutura dos currículos acadêmicos destes profissionais no que diz respeitos às disciplinas de humanidades, de acordo com os autores, tal lacuna repercute em dois sentidos, o primeiro, como abordado no artigo anterior revela o despreparo dos profissionais para tratar da finitude do outro e o segundo intrinsecamente ligado ao primeiro provoca angustia, dor e depressão nos próprios profissionais da saúde, principalmente naqueles que trabalham diretamente com pacientes terminais.

Essa questão é definitivamente muito complexa, pois, envolve do ponto de vista epistemológico a própria constituição do conhecimento biomédico, uma ciência fundamentada na concepção de preservação da vida a qualquer custo, atualmente, aparada por um amplo espectro de equipamentos e tecnologias medicamentosas de ponta, não aceita a morte e não consegue integrá-la no seu repertório de condutas, pois a morte representa falibilidade do seu ofício.

Desse modo, o desafiar a morte, as tentativas heroicas para salvar o paciente a todo custo, é uma postura comum na equipe de saúde contradizendo o cuidar humanizado. Por diversas vezes pacientes são levados até emergência, há uma invasão de sua privacidade, de seus direitos. Vários procedimentos são feitos e, então, enfim, salvamos. Quem? Nós mesmos? Nossos egos de não admitir a morte naquele ambiente e de não aceitarmos que somos falíveis, finitos? E se aqueles que ali estão sendo manipulados não quiserem viver? Que doenças os assolam? Primeiro usamos a tecnologia, depois verificamos as possibilidades terapêuticas. (SANTOS et al, 2014, p.199)

Não temos dúvidas da profundidade deste assunto, tendo em vista o fato de vivermos numa sociedade que hipervaloriza a vida, a saúde, o bem estar a qualquer custo, uma sociedade que desde o século XIX, como apontamos anteriormente, construiu por meio do controle do conhecimento biomédio a ideia de que existe a possibilidade do domínio sobre a vida, sobre a saúde e sobre a doença, um conhecimento que não consegue tratar do imponderável, do imprevisível e da inevitabilidade da morte e tudo o que ela traz consigo. No entanto, ironicamente, a morte desnuda os limites do conhecimento biomédico, pois não se consegue 
evitá-la, tornando-se o centro de uma frustração coletiva diante dos limites da racionalidade científica moderna.

Existe um ramo do conhecimento na área da saúde coletiva que gradativamente está se tornando uma política pública que são os Cuidados Paliativos, seu ideário é analisado no artigo de Raquel Aisengart Menezes (2013) e Patrícia de Castro Barbosa (2013) “A construção da 'boa morte' em diferentes etapas da vida: reflexões em torno do idearia paliativista para adultos e crianças”, as autoras parem do exame de livros-textos, manuais e observação de cursos e congressos que tratam deste ramo da ciências da saúde preocupado com o desenvolvimento de uma série de cuidados voltados para pacientes "fora de possibilidade terapêutica de cura" nessa abordagem os protocolos de cuidados são fundamentados numa perspectiva de assistência à "totalidade bio-psico-social-espiritual" do paciente e de seus familiares com o objetivo fundamental de proporcionar-lhes - a todos os envolvidos qualidade de vida do tempo restante.

Por séculos, a morte passou a ser cada vez mais isolada socialmente, conduzindo ao que Louis-Vicent Thomas nomeou de "uma crise da morte no mundo contemporâneo ocidental (1). Norbert Elias considerou tratar-se da produção de isolamento e solidão dos "moribundos" (2). O século XX assistiu uma administração da morte na qual a medicina, com novas tecnologias, se tornou responsável pela redução de algumas taxas de mortalidade, como a infantil e a neonatal, e pelo prolongamento da vida. Ao mesmo tempo, com as medidas de prevenção e controle social da saúde e da doença, a medicina desempenha posição central no afastamento da morte das consciências individuais. O conhecimento da implacabilidade dos processos naturais é aliviado pela noção de que eles são - e busca-se que sejam mais e mais - controláveis. ( MENEZES e BARBOSA, p. 2654)

Historicamente o ideário dos Cuidados Paliativos se originou nos Estados Unidos na década de 1960 e estão vinculados aos movimentos políticos pelos direitos civis, que entres outras reivindicações levantava a questão direito a autonomia dos doentes em relação à própria morte $\mathrm{e}$ criticavam as relações de poder entre médicos e pacientes. Na década de 1970 o movimento Nova Era e a perspectiva da espiritualidade passou a ter forte influência na proposta dos Cuidados Paliativos principalmente 
no que diz respeito à visão da vida como fluxo " no qual está inserido um individuo singular, cuja interioridade é tido como lócus de sua verdade." ( Ibidem, p. 2655)

Dessa forma, o que se apresenta de novo - não pelo fato de ser recente - é a perspectiva de considerar questões de natureza espirituais no processo de enfrentamento da finitude humana e em seus desdobramentos como no transcorrer do luto. Obviamente existe uma série de questões em relação à presença ou a inserção de perspectivas espirituais no âmbito de tratamentos médicos, porém é necessário enfatizar que, de acordo, com as autoras:

A Organização Mundial de Saúde auxilia a divulgação do movimento paliativista, por seu Programa de Controle do Câncer e publicação de manuais, como o Cancer pain relief and palliative care report em muitos idiomas. Assim, os Cuidados Paliativos cada vez mais assumem posição de destaque no Ocidente no que diz respeito ao enfrentamento dos desafios do acompanhamento de enfermos no processo do morrer. (Ibidem, p. 2659)

Embora seja fundamental o reconhecimento dos Cuidados Paliativos pela Organização Mundial de Saúde, ainda assim, consideramos que há um longo percurso no processo de humanização da morte no Brasil e no mundo, sobretudo no que diz respeito às questões religiosas e ou aos sistemas de crenças comor referências de vida e de morte.

O site Rede Humaniza SUS ${ }^{4}$, do atendimento básico de saúde brasileira, aponta que os espaços para o aprendizado da morte são exíguos devido à ausência de um projeto socializador diante da morte. Indica, ainda a necessidade urgente de um projeto que reinvente a imagem da morte pelo registro absolutamente negativo como as representações de caveiras, corpos em decomposição, mundo atormentado por zumbis. E nesse processo de reumanização da morte, os conteúdos religiosos assumem papel central. As elaborações do luto e da perda são, ao mesmo tempo, individuais, mas também parte de uma dinâmica social, a qual era conhecida desde muito tempo pelo curioso hibridismo religioso brasileiro, por exemplo, que maneja coletivamente estas questões. Para onde foi, na contemporaneidade secularizada, o caráter coletivo e

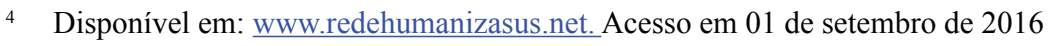


socializador referente à morte e seus conteúdos simbólicos? De quem é a responsabilidade por manejar estes conteúdos na saúde pública?

Em relação a essas perguntas queremos apontar algumas reflexões sobre a morte e seu processo de elaboração. Atualmente essa é uma questão, entre outras coisas, de saúde coletiva, não podemos deixar de considerar que as pessoas morrem em hospitais, às vezes não assistidas por parentes, seus corpos são levados para IMLs, casas funerárias e somente a partir desse momento é que os parentes e amigos do defunto retomam o seu contato com ente que desapareceu na morte. Nessa dinâmica pouco ou quase nenhum momento o processo de acompanhamento do moribundo que chega a falecer passa pelo amparo da família e amigos. E em relação a essa presença, retomando as questões que o blogueiro do reumaniza SUS faz, observa-se que falta processo educacional para enfrentar a morte. Tal enfrentamento, como se vê, é abordado ainda de maneira tímida nas políticas públicas de saúde e o manejo dos conteúdos religiosos e simbólicos não parece considerado neste processo.

\section{Morte e luto como construção psicossocial, histórica e religiosa}

Todos os dias que depois vieram eram tempo de doer. Miguilim tinha sido arrancado de uma porção de coisas, e estava no mesmo lugar. Quando chegava o poder de chorar, era até bom - enquanto estava chorando parecia que a alma toda se sacudia, misturando ao vivo todas as lembranças, as mais novas e as muito antigas. Mas, no mais das horas, ele estava cansado. Cansado e como que assustado. Sufocado. Ele não era ele mesmo. Diante dele, as pessoas perdiam o peso de ser. Os lugares, o Mutum - se esvaziavam, numa ligeireza, vagorosos. E Miguilim se achava mesmo diferente de todos.

João Guimarães Rosa. Manuelzão e Miguilim, 2013.

O luto é um processo considerado como parte do desenvolvimento psíquico "normal" diante de perdas e abandonos. Apesar desta constatação psicológica feita por autores psicanalistas clássicos, como Freud (2014 [1915]) e Maria Rita Kehl (2011)5 há que se reconhecer o estado

\footnotetext{
5 "O trabalho psíquico empreendido pelo enlutado, embora empobrece o ego e torne o sujeito inapetente para quaisquer outros investimentos libinais, pode ser considerado um trabalho de saúde psíquica. É um trabalho paulatino de desligamento da libido em relação ao objeto de prazer e satisfação narcísica que o ego perdeu, por morte ou abandono" (KEHL, 2011)
} 
fronteiriço do luto entre a normalidade e a patologia. Como na citação de Guimarães Rosa, o estado do enlutado é um não lugar. Envolve um deslocamento social e emocional, e especialmente, identitário, que causa estranhamento ao cotidiano de nossas atividades comuns. O luto pode tornar-se patológico em determinados contextos, em especial quando há prolongamento do apego ao ser ou situação perdida. Nesse sentido, há que se preocupar coletivamente, com medidas de saúde pública que apoiem o desenvolvimento adequado dos processos de luto.

A literatura aponta para um empobrecimento simbólico e ritual dos processos de morte e de luto na contemporaneidade (MARTINS, 2005; GAMBINI, 2005), uma vez que a morte passou a ser negada, por representar um limite à pretensa autossuficiência da humanidade. O tal "tempo de doer" vivenciado por Miguilim na obra de Guimarães Rosa entra em contraste com o tempo da sociedade civilizatória, para a qual o não-lugar, o estranhamento, o deslocamento dos enlutados são vistos como improdutivos. A morte, neste sentido, torna-se adversária da vida, e não parte de seu curso natural (FRANCO, 2007).

José Carlos Rodrigues em seu trabalho Tabu da Morte (2006) demonstra de uma forma geral como o processo de industrialização da sociedade contemporânea esvaziou o conteúdo religioso da morte como elaboração de um projeto coletivo de enfrentamento do caos provocado pela morte, para o autor as sociedades industrializadas tornaram-se sociedades centradas no indivíduo e na produção de uma mentalidade social de extrema valorização da vida por meio da criação de quatro mitos: o mito da extrema riqueza; o mito da extrema capacidade produtiva da sociedade moderna; o mito do progresso e o mito da vida. Assim em função dessas concepções o século XX no mundo ocidental acabou por afastar a morte do convívio social, no entanto, apesar de todos esses esforços a ciência ainda não conseguiu vencer a morte, apesar da ideologia reinante de que nossa sociedade é uma sociedade que propicia o florescimento da vida.

Enfim, o mito da vida, a crença na ideia de que, mais que em qualquer outro lugar, nossa sociedade é o terreno propício para o florescimento da vida. Este mito contém o pensamento de que podemos produzir vida, graças a nossa ciência médica, a nossa agricultura, a nossa zootecnia e a nosso 'progresso'. Este mito é o banimento da ideia da morte, a postula- 
ção da imortalidade e da a-mortalidade humana. É o mito fundamental, síntese de todos os outros, o caminho que nos leva à compreensão do tabu com que envolvemos a morte e ao entendimento das estratégias pelas quais escondemos nossas dimensões da Morte. (RODRIGUES, 2006, P.274)

Sem dúvida numa sociedade estruturada desta forma o "tempo de doer" é um tempo inútil se dedicado a elaborar e compreender a antítese da vida, no entanto, nem sempre as relações foram dessa forma, não queremos com essa afirmação entrar no discurso do "saudosismo do passado", nossa intenção ao contrário é elaborar uma reflexão crítica das relações contemporâneas com a morte, principalmente no que concerne a um tratamento de compreensão do processo de luto como uma política pública, portanto, coletiva e ao mesmo tempo demonstrar historicamente o que significou a desconstrução das expressões religiosas em torno do luto como elaboração da morte como afastamento ou esquecimento dos rastros históricos interculturais que fundamentaram o sentido da morte e do morrer no Brasil.

Até o início do século XX a morte era um fator de comoção social que sempre se exprimia por meio de uma série de comportamentos rituais notadamente de matrizes religiosas diversas para que a comunidade e seus membros conseguissem se reencontrar diante do caos provado pela morte de um de seus membros. Dessa forma, a produção de um repertório simbólico de enfrentamento do luto por morte se insere na perspectiva do ethos religioso brasileiro, entendemos por ethos a definição de Clifford Geertz (2015) "O ethos de um povo é o tom, o caráter e a qualidade de sua vida, seu estilo moral e estético" (p.93) e acrescentando à ideia de ethos como o tom de povo trazemos o pensamento de Maria Lúcia Montes (2012) que defende a tese de que o ethos religioso brasileiro se produziu a partir das referências culturais afro-amerídias-cristãs.

Dessa forma, o repertório religioso elaborado durante pelo menos 4 séculos é o resultado de uma profunda relação dessas cosmovisões que se entrelaçaram numa mistura curiosa orquestrada pela Igreja Católica que atuando na vida pública em função de seus vínculos com o Estado foi capaz de legitimar o poder e a dominação, ao mesmo que se adaptava a crenças africanas e ameríndias, sendo assim, poderíamos 
afirmar que temos tais repertórios registrados em nossa memória social e estes foram relegados ao esquecimento por não se enquadrarem nas demandas do mundo contemporâneo.

Podemos afirmar que se produziu uma política do esquecimento ${ }^{6}$ deste repertório que é decorrente, entre outros fatores, da não aceitação do papel da morte na vida contemporânea. O tabu da morte (RODRIGUES, 2006) traz o mal-estar da impotência humana e coloca o luto como um processo anormal, quando este faz parte do desenvolvimento da saúde psíquica diante da morte. Tal inversão faz com que o enlutado, além do isolamento natural de seu processo, também sofra uma pressão por saída deste estado improdutivo.

É preciso, portanto, criar e construir repertórios sociais e coletivos sobre a morte. Falar, produzir significados partilhados, oferecer legitimidade ao não-lugar dos/as enlutados/as. Assim como é preciso construir estes espaços públicos para se abordar a morte, é preciso se ampliar o manejo dos conteúdos religiosos diante de questões centrais na construção identitária como é o caso de perdas por morte. As religiões têm sido apartadas dos espaços e das políticas públicas, até em temas em que seu espaço é estrutural, como este.

Por isso, reforçamos uma ideia abordada anteriormente de a ausência do manejo dos conteúdos religiosos nos processos sociais de elaboração do luto pode ser compreendida como parte de um grande projeto de modernidade e laicidade, no qual as religiões precisam estar apartadas dos espaços públicos, à luz de uma racionalização que não permite espaço para a mediação e elaboração simbólicas. Neste sentido, a lacuna das religiões nas estratégias públicas de saúde para lidar com a morte é a lacuna simbólica, a ausência de um canal psíquico de elaboração.

E neste sentido concordamos com o antropólogo americano Clifford Geertz (2015) que há pelo menos três pontos nos quais o caos ameaça o homem: a perplexidade, o sofrimento e um sentido de paradoxo ético esses três pontos quando se tornam suficientemente intensos ou suportados durante muito tempo, de acordo com o autor, se tornam desafios radicais a qualquer proposição de que a vida é compreensível

6 RICOEUR, Paul. A memória, a História e o Esquecimento. Campinas (SP): Editora da Unicamp, 2007. 
e de que podemos orientar-nos efetivamente dentro dela. Sendo assim, aponta que as experiências religiosas por meio da produção de um grande repertório simbólico mobilizado a partir de conjuntos ritualísticos de alguma forma produz uma espécie de acomodação capaz de trazer inteligibilidade ao sofrimento.

Para um antropólogo, a importância da religião está na capacidade de servir, tanto para um indivíduo como para um grupo, de um lado como fonte de concepções gerais, embora diferentes, do mundo, de si próprios e das relações entre elas - seu modelo da atitude - e de outro, das disposições mentais enraizadas, mas nem por isso menos distintas - seu modelo para a atitude - A partir dessas funções culturais fluem, por sua vez, as suas funções sociais e psicológicas. (GEERTZ, 2015, p.90).

Portanto, as expressões religiosas historicamente constituídas no Brasil formularam modelos de atitudes e para atitudes (Geertz, op. cit) diante da morte e do luto, que pode ser compreendido com um período de acomodação e reorganização do caos provocado pela morte, desde o Brasil colônia, o luto era um momento partilhado socialmente e a sua instituição era informada por um amálgama de matrizes de crenças (afro-ameríndia e cristã) que eram parte constituinte da vida ordinária da sociedade colonial e posteriormente da sociedade pós-independência e podemos dizer que tais matrizes informaram a produção do que denominamos religiosidade brasileira.

Por meio da imbricada relação entre essas matrizes o luto como expressão coletiva de dor e consternação se produziu no Brasil, essas representações se materializavam, por exemplo, no vestuário das famílias que de acordo com o grau de parentesco usavam preto por um período de seis meses a um ano, inclusive havia uma legislação colonial que normatizava o tempo do luto (REIS, 1991, p.133), ao mesmo tempo em que o vestuário do luto marcava a presença de pessoas enlutadas na comunidade, do ponto de vista doméstico fazia parte das tradições em várias comunidades brasileiras apagar os rastros do morto logo após o enterro.

O fato é que existe a produção de uma concepção de luto que se constrói historicamente no Brasil e que se inscreve no que podemos nomear como ethos religioso brasileiro, entendendo ethos a partir de 
visão antropológica elaborada por Clifford Geertz (2015) como um conjunto de aspectos morais e estéticos de uma dada cultura, e a partir deste ethos religioso historicamente a sociedade brasileira forjou a produção de práticas de crenças por meio das relações estabelecidas entre cristãos, africanos e indígenas, obviamente relações que se estabeleceram por meio da força e das tentativas de imposição de uma cultura sobre a outra, mas que ao mesmo tempo produziram resistências e fórmulas de escapes durante esse processo.

O pós-colonialista Homi Bhabha (1998), considera que o hibridismo seria uma marca da resistência das identidades, narrativas e subjetividades não fixas. Os "entrelugares” fornecem bases para a elaboração de estratégias de subjetivação a partir de novos referenciais e signos de identidade. Bhabha (1998, p.78), enxerga uma condição de negociação inscrita no funcionamento de revisar a tradição a partir de hibridismos. Esta perspectiva de fronteira e entrelugares marca experiências de negociação que transitam entre a fixidez esperada em identidades tradicionais e os processos de subalternidade que desafiam estruturas definidas.

Nessa perspectiva do hibridismo, o ethos religioso brasileiro traz marcas de uma resistência diante de demandas modernas de secularização, racionalidade das crenças, laicização e empobrecimento ritual e simbólico. E esta resistência das narrativas religiosas se evidencia diante da morte, quando podemos indicar que no universo mortuário brasileiro os rituais de luto aparecem de maneira bastante semelhante fundamentalmente no que diz respeito ao resguardo dos enlutados, da mobilização da solidária da comunidade em torno dos enlutados e da necessidade de cerimônias religiosas, sejam missas ou cultos.

Nas culturas africanas (Del PRIORE, 2014) e indígenas ( FLECK, 2014) o processo do que chamaríamos de luto compreende uma série de rituais que tem por objetivos contribuir para a partida definitiva do morto para o mundo do além, ao mesmo tempo que esses rituais contribuem para que a comunidade e os familiares do morto retomem o equilíbrio social, por isso, no caso das culturas africanas os rituais costumam durar até três meses, como havia entre alguns povos indígenas a necessidade de que o sofrimento por luto deve ser exposto publicamente. 
Durante todo o processo de colonização do Brasil o cristianismo católico pós Concílio de Trento tinha como perspectiva um projeto de conversão a principio dos povos indígenas e posteriormente quando a escravidão africana foi assumida como mão de obra no país, começou um processo de conversão dos africanos que chegavam ao Brasil via o tráfico de escravos, no entanto, essa política de conversão ao cristianismo como entende Eliane Fleck (2014) deve ser considerado um longo processo de adaptação em que a adesão dos índicos guaranis aos rituais cristãos não implicou o abandono de suas crenças religiosas, pois, o que ocorreu foi uma adaptação da doutrina cristã às necessidades psíquicas dos povos indígenas criando novas sensibilidades religiosas tanto para o europeu cristão quanto para os indígenas.

Portanto, em muitos países, mas especialmente no Brasil, seria superficial abordar a morte e os processos de enfrentamento do luto sem considerar os elementos religiosos que são componentes fundamentais na formação da sociedade brasileira, além de caracterizarem-se como elemento de resistência identitária. Ao nos depararmos com o Sistema Único de Saúde retomando, de certo modo, ideias medievais da Igreja Católica como a do bem morrer (Cf. ARIÉS, 2003), preocupando-se com a construção de uma pedagogia para a morte, seria de grande valia o repertório da Ciência das Religiões, que trariam com profundidade, aspectos históricos, sociais, psicológicos entrelaçados com a perspectiva religiosa. Tanto o "bem morrer" quanto a pedagogia da morte são partes integrantes da complexa religiosidade popular no Brasil.

Por isso, retomamos a observação da José Carlos Rodrigues (2006), indicada anteriormente, em relação ao fato de que a sociedade contemporânea esvaziou a morte de seu conteúdo religioso, sem cairmos em afirmações ingênuas, e entendendo a dimensão vasta que o processo de secularização da sociedade brasileira representa e representou no último século, ainda ficamos com a afirmativa de que não podemos desconsiderar os elementos religiosos quando se fala em morte no Brasil, como também não podemos desconsiderar que a morte no último século passou do controle religioso para o controle médico e é justamente o controle médico - pelo menos parte dele - que está revendo suas posições em relação aos procedimentos diante da morte. 


\section{A produção acadêmica das Ciências das Religiões sobre a morte e o luto}

A partir do que foi mencionado no item anterior é fundamental indicar que existe uma significativa produção acadêmica na área das Ciências das Religiões que trata os mais variados temas em relação à morte, boa parte desses trabalhos são resultados de pesquisas que abordam as práticas religiosas do "bem morrer", rituais funerários, arte tumular, simbologia mortuários em diversas sociedades como já apontamos anteriormente.

Mas é incontestável que estas temáticas também estão presentes em trabalhos de historiadores, antropólogos e sociólogos, no entanto, a grande maioria dos trabalhos sobre o luto - como seus conceitos, imagens e representações - localizam-se no campo de conhecimento da psicologia. Siqueira et al (2016) elaboraram um estudo sobre o estado da arte da produção acadêmica sobre o luto no Brasil, os autores realizaram análise dos resumos das teses sobre luto no período entre 2007 e 2013 a partir do banco de dados do BDTD (Biblioteca Digital de Teses e Dissertações do IBICT -Instituto Brasileiro de Informação em Ciência e Tecnologia). Este trabalho aponta para algumas questões interessantes, em primeiro lugar corrobora com nossas avaliações preliminares de que boa parte da produção acadêmica sobre o luto insere-se no campo da psicologia, além disso, a maioria dos trabalhos está concentrada em São Paulo e são quase inexistentes trabalhos que se debruçam sobre as experiências de luto entre crianças e doentes mentais. Mais interessante ainda é o fato de que sequer citam trabalhos que tratem da temática do luto sob a perspectiva religiosa ou mesmo trabalhos de Cientistas da Religião o que é uma lacuna na referida pesquisa.

Portanto, trazemos para nossa reflexão o trabalho de Paula Blanches (2009) Corpos Enlutados: por um cuidado terapêutico em situações de luto analisa o fenômeno de luto por morte a partir da fenomenologia por meio das experiências de luto vividas pelos membros da Igreja Metodista do Grande $\mathrm{ABC}$, sua preocupação foi demonstrar que a situação de luto por morte do ponto de vista fenomenológico é efetivamente vivido por meio das relações religiosas. 
A pesquisa que envolve o fenômeno luto vem de perguntas existenciais trazidas pelos membros da igreja que aconselham e da busca de amparo nos tratos das pessoas. A indagação diante do tema é: qual ou quais os caminhos que poderiam nos ajudar a aprofundar a reflexão e realizar a pesquisa sobre o luto. Diante dessa inquietação encontramos o método fenomenológico como vimos na primeira parte desta tese, o método fenomenológico advém de uma busca pela essência das coisas. Ao empreender a fenomenologia como método Hurssel ofereceu um outro caminho para a busca do conhecimento em que o mundo da vida está estreitamente ligado à construção do conhecimento. (BLANCHES, 2009, p.113)

A partir desta perspectiva os resultados alcançados por Paula Blanches são fundamentais para a Ciência da Religião, pois, a autora demonstra a construção de um saber em torno da experiência do luto por morte que se assenta na possibilidade da teologia cristã em ressignificar a morte por meio da criação de uma teologia da perda, assim, o espaço no interior das comunidades religiosas viabiliza a produção de uma educação cristã voltada para o enfrentamento do luto.

Numa perspectiva diferenciada de Paula Blanches o trabalho de Leonildo Campos Silveira (2016) Protestantes Brasileiros diante da morte e do luto analisa certo esvaziamento religioso nos ritos mortuários entre os protestantes brasileiros de várias denominações, o autor aborda que a concepção e compreensão da morte e do morrer exerce no distanciamento da cosmovisão cristã entre católicos e protestantes e demonstra como essa estrutura ritual em torno da morte se constrói por meio da leitura da Bíblia e de manuais que orientam os ofícios mortuários fundamentalmente entre presbiterianos e metodistas. A estrutura desses rituais consiste em gratidão pela vida do morto, pedidos de intercessão pelos enlutados, porém de acordo com o autor o foco do ritual centra-se nos vivos e não nos mortos e esse é um traço comum entre os protestantes.

Nos rituais mortuários de protestantes há muitas leituras bíblicas, reflexões, preces e cânticos, tanto no culto, nos rituais com a presença do corpo no templo ou no local de velório, como também no cemitério. Isso torna tais rituais diferentes dos rituais católicos ou de outras religiões. Nessas ocasiões, trechos da Bíblia Sagrada são usados no esforço de consolar os entristecidos pela morte de um ente querido e de reanimar neles a vontade de viver. Nesses rituais há textos bíblicos preferidos, 
como: Lembre do seu Criador enquanto você ainda é jovem, antes que venham os dias maus e cheguem os anos em que você dirá: "Não tenho mais prazer na vida". (...) "Nós estaremos caminhando para o nosso último descanso; e, quando isso acontecer, haverá gente chorando por nossa causa nas ruas. A vida vai se acabar como uma lamparina de ouro cai e quebra; quando a sua corrente de prata se arrebenta; ou como um pote de barro se despedaça quando a corda do poço se parte. Então o nosso corpo voltará para o pó da terra, de onde veio, e o nosso espírito voltará para Deus, que o deu. É ilusão, é ilusão, diz o Sábio. Tudo é ilusão". (Eclesiastes 12:1- 8). (SILVEIRA, 2016, )

Uma questão de extrema importância analisada por Leonildo Campos Silveira em relação ao processo de enfrento do luto por protestantes reside no fato de que o protestantismo está intimamente envolvido no processo de secularização da sociedade brasileira, assim, contribuindo para a formulação de expressões religiosas diante da morte de maneira intimista e privada uma antítese dos rituais mortuários, incluindo o luto, expresso pelo catolicismo barroco. Além disso, os contextos contemporâneos de formulação dos ritos mortuários prescindiram dos elementos religiosos, o que já estudou o antropólogo José Carlos Rodrigues (2006) em Tabu da Morte quando atenta para o esvaziamento religioso dos destes rituais, como já abordamos anteriormente.

Estaríamos vivendo o fim dos rituais religiosos mortuários? O processo de secularização, para o qual houve uma forte influência protestante, estaria nos levando para longe das estratégias e dos rituais articulados há séculos pelos religiosos no que se relaciona à morte? Mitchel escrevendo sobre o impacto das mudanças sobre as liturgias cristãs, afirma que há no cenário cultural "rituais emergentes" em erupção em nossa sociedade. "Os rituais continuam sendo uma poderosa força a moldar as crenças, porque nos animam a interpretar a realidade de determinadas maneiras". Poderá haver uma diminuição na busca das igrejas para a prestação desse tipo de serviço ainda hoje requerido dos clérigos? Parece que sim, inclusive os rituais de luto se tornam cada vez mais breves e restritos a um círculo muito pequeno de pessoas. (SILVEIRA, 2016, pp.166-167)

Dessa forma, consideramos os trabalhos de Paula Blanches e Leonildo Campos Silveira importantes referências do ponto de vista da Ciência da Religião para elaborarmos algumas considerações das formulações da morte sob o olhar do (a) cientista da religião, Paula Blanches 
por meio do estudo da das vivências do luto por morte na comunidade Batista a fundamental importância da produção de uma espiritualidade, uma educação cristã, como indica a autora, que busque a valorização da vida em meio as perdas, portanto, a religiosidade é central sob esta perspectiva. Leonildo Campos Silveira, também, ressalta a importância da liturgia cristã nos rituais mortuários - não necessariamente o luto - nas comunidades presbiteriana e metodista, no entanto, o autor demonstra a presença com o objetivo de enfatizar o seu esvaziamento.

\section{Considerações finais}

Para dar a todos os Miguilins o direito ao seu não-lugar do luto e para que seu estranhamento advenha somente do já tão desgastante processo de luto e não dos conteúdos de julgamento externos vindos da não compreensão e do não acolhimento da sociedade para com o enlutado, apresentamos esta proposta de atuação do/a cientista da religião nas políticas públicas de saúde do Brasil, que visa compor as equipes multidisciplinares de saúde, por meio de ações como rodas de conversa e grupos de apoio, tratando da temática da morte de maneira ampla. $\mathrm{O}$ repertório dos estudiosos das religiões oferece uma interlocução com um universo simbólico particular, que, no atual modelo de saúde, não tem sido adequadamente contemplado.

Sob a ótica das demandas apresentadas pelos profissionais da área da saúde em relação ao despreparo destes profissionais diante do enfrentamento da morte e luto, fica, pelo menos preliminarmente indicada algumas ausências, em primeiro lugar foi detectado um problema indicado alguns pontos críticos deste despreparo, quanto a formação profissional e quanto as abordagens em relação aos pacientes e suas famílias. Sem dúvida algumas dois aspectos fundamentais de políticas públicas de um lado políticas públicas na área da Saúde e de outro lado políticas públicas na área de Educação.

Mas ainda há uma questão de fundo em torno destas políticas públicas, principalmente em relação às suas orientações, pois, em nenhum momento os profissionais da saúde, aqui abordados, levaram em consideração as crenças religiosas como um elemento fundamental para o enfrentamento da morte e do luto no Brasil, a exceção do artigo 
de Raquel Aisengart Menezes e Patrícia Barbosa que indicam que na assistência dos Cuidados Paliativos existe a compreensão da dimensão espiritual que norteia a vida do paciente e de suas famílias, porém, se esquece de mencionar que a próprio conceito de "bem morrer" é um conceito criado pelos jesuítas que ao longo dos séculos XVII e XVIII, elaboraram centenas de publicações de manuais da boa morte, o que a historiografia denomina de pedagogia do "bem morrer."

E nesse sentido lembramos que a Organização Mundial de Saúde entende que o bem-estar espiritual faz parte da perspectiva de saúde integral do ser humano, nada mais representativo que o tema da morte para nos colocar diante do universo particular de significados espirituais. E ninguém mais indicado que este/a profissional das religiões para realizar o manejo destes universos particulares de significado, devolvendo a Miguilim um processo de luto com amparo social.

Por isso, para compreender a estatura que a temática da morte assume na sociedade brasileira é preciso compreender historicamente o papel que as religiões e a religiosidade ocupam na vida ordinária dessa sociedade, pois num processo de longa duração da história há uma profunda continuidade de estruturas significativas nas quais se filiam as marcas da religião, essas marcas delimitam as fronteiras entre o público e o privado nas formas de expressão desta religiosidade que tem na morte uma temática importante para além das instituições que as moldaram originalmente, e talvez, inclusive, da inexorável lógica do 'mercado de salvações' (MONTES, 2012)

Sendo assim, se por um lado é necessário um mergulho na investigação das práticas do luto que se desenvolveram no Brasil a partir de um hibridismo étnico-religioso, e, portanto, é fundamental compreender os processos por meio dos quais esse hibridismo se conformou, mas é também é tão necessário quanto que percebamos a que nos referimos quando tratamos de matrizes cristãs e afro-ameríndias e como estas matrizes produziram o que estamos denominando de ethos religioso brasileiro.

E dessa maneira os (as) cientistas das religiões podem e devem atuar como docentes em cursos de graduação nas diversas áreas do

Sobral, Luciana O. Gama. Op. Cit. pp. 22-28. 
conhecimento em saúde, participar de equipes multiprofissionais que atendem pacientes em Cuidados Paliativos, atuarem como consultores na formulação e desenvolvimento de políticas de saúde como o projeto Reumaniza SUS, pois, como profissionais que se debruçam sobre os fenômenos religiosos - sem profissão de fé - e os estudam como um traço fundamental das relações sócio-culturais-políticas-ideológicas em qualquer sociedade, pois, enquanto a Educação e Saúde Pública não reconhecerem o papel que as religiões e a religiosidade desempenharam na elaboração dos sentidos da morte, do morrer e do luto no Brasil haverá sempre lacunas na formação de profissionais e no atendimento em saúde num momento crucial na vida de qualquer ser humano, que é justamente o momento de sua morte.

Somando-se a essas observações preliminares indicamos ainda, que pensar sobre a atuação dos (as) cientistas da Religião no processo de elaboração de políticas públicas de saúde voltadas ao enfrentamento do luto, significa também enfrentar um embate histórico entre o discurso médico-científico e as expressões religiosas, ao se colocar neste contexto os (as) cientistas da Religião devem conhecer os meandros desse embate que no Brasil se instituiu há quase 200 anos e está estritamente vinculado a um jogo de poder pelo controle das ações do Estado, obviamente, as concepções médicas em relação às crenças religiosas se alteraram durante esses séculos e se o conflito não existe de forma tão latente, existe um mito acerca do conflito que permanece no imaginário coletivo de nossa sociedade. Assim, essa aproximação do (a) cientista da Religião com a "assistência médica" cumpre inúmeros papéis além de contribuir e instrumentalizar profissionais da saúde acerca do universo do conhecimento das religiões e religiosidades no Brasil, também, pode atuar no sentido colocar a importância crucial que as religiões e a religiosidade encerram na formação social, política e cultural da sociedade brasileira.

Sendo assim, apresentamos nessa reflexão focada no processo de luto, algumas considerações a respeito do trabalho do/a cientista da religião. Nossa proposta é de que podemos (e devemos) atuar do ponto de vista profissional compondo equipes multidisciplinares que contribuam com a proposta do SUS no sentido de reumanizar a morte, afinal, como cientistas das religiões temos no repertório de nossa formação 
profissional conhecimentos especializados que podem contribuir com a elaboração de significados simbólicos próprios da morte e do luto.

Neste sentido, indicamos que o/a cientista das religiões se aproprie deste lugar de mediação e manejo dos repertórios simbólicos, culturais e religiosos, envolvidos na temática da morte, que evocam conteúdos como as reflexões sobre a origem e o destino dos seres humanos, o tipo de experiência a que estamos submetidos quando a existência é colocada em seus limites, elaborações sobre a finitude corporal e as possibilidades de um duplo espiritual, sentimentos ancorados em crenças e visões de mundo... E, a partir deste lugar de mediação e manejo, faz-se necessário ampliar os espaços públicos de discussão e elaboração da morte em suas várias formas (suicídio, mortes repentinas, mortes por doenças prolongadas, mortes por velhice, desastre, de jovens...), cada qual com seu simbolismo próprio no campo das crenças.

\section{Referências Bibliográficas}

ARIÉS, Phillipe. Sobre a História da Morte no Ocidente: da Idade Média aos Nossos Dias. Rio de Janeiro: Ediouro, 2003.

Del PRIORE, Mary. Morte e fronteiras culturais: passagens, rituais e práticas funerárias entre ancestrais africanos (outra lógica da finitude). (Capítulo do livro em preparação sobre a história da morte no Brasil). In: RODRIGUES, Claudia e LOPES, Fábio (orgs) Os sentidos da Morte e do Morrer na Ibero América. Rio de Janeiro,EduERJ, 2014.

BHABHA, Homi K. O Local da Cultura. Belo Horizonte: UFMG,1998.

BLANCHES, Paula. Corpos Enlutados: Por um cuidado espiritual terapêutico em situações de luto.Tese de Doutorado. Universidade Metodista de São Paulo. São Bernardo do Campo.2009.

FLECK, Eliane Cristina Deckman. Sentir, adoecer e morrer nas reduções jesuítico-guaranis (Província Jesuíta do Paraguai, século XVII) In: RODRIGUES, Claudia e

LOPES, Fábio (orgs) Os sentidos da Morte e do Morrer na Ibero América. Rio de Janeiro,EduERJ, 2014.

FRANCO, Clarissa De. Crise criativa no morrer: a morte passa apressada na pós-modernidade. Revista Kairós, São Paulo, 10(1), jun. 2007, pp. 109-120.

FRANCO, Clarissa De. A Cara da Morte. São Paulo: Ideias e Letras, 2010. 
FREUD, Sigmund. Luto e melancolia. São Paulo: Cosac Naify, 2014.

GAMBINI, R. "A morte como companheira". In: OLIVEIRA, M. F. e CALLIA, M. H. P. (orgs.). Reflexão sobre a morte no Brasil. São Paulo, Paulus, 2005.

GIACOMIN, Referência Giacomin et al. Ciência \& Saúde Coletiva, 18(9) : 2487- 2496, 2013.

GEERTZ, Clifford. A Interpretação das Culturas. Rio de Janeiro: LTC, 2015. GUIMARÃES ROSA, João. Manuelzão e Miguilim. Rio de Janeiro: Nova Fronteira, 2013.

KEHL, Maria Rita. "Melancolia e Criação" Em: KEHL, Maria Rita; PERES, Urania T.; CARONE, Modesto e CARONE, Marilene (tradução de Marilene Carone). Resenha de Freud, Sigmund. Luto e Melancolia. São Paulo: Cosac Naify, 2011, 144 p.

MARTINS, J. S. "Anotações do meu caderno de campo sobre a cultura funerária no Brasil”. In: OLIVEIRA, M. F. e CALLIA, M. H. P. (orgs.). Reflexão sobre a morte no Brasil. São Paulo, Paulus, 2005.

MENEZES, Raquel Aisengart e BARBOSA, Patrícia de Castro. A construção da "boa morte" em diferentes etapas da vida : reflexões em torno do idearia paliativista para adultos e crianças. In: Ciência \& Saúde Coletiva, 18(9):2653-2662, 2013

Apresentação. In: RODRIGUES, Claudia e LOPES, Fabio.

(orgs) Sentidos da Morte e do Morrer na Ibero-América. Rio de Janeiro: EdUERJ, 2014.

MONTES, Maria Lúcia. Figuras do Sagrado: entre o público e o privado na religiosidade brasileira. São Paulo: Claro Enigma. 2012.

RICOEUR, Paul. A memória, a História e o Esquecimento. Campinas (SP): Editora da Unicamp, 2007.

REIS, João José. A morte é uma festa: ritos fúnebres e revolta popular no Brasil do século XIX. São Paulo: Companhia das Letras, 1991.

RODRIGUES, Claudia. Nas Fronteiras do Além. A secularização da Morte no Rio de Janeiro: (séculos XVIII e XIX). Rio de Janeiro. Arquivo Nacional. 2005.

RODRIGUES, José Carlos. Tabu da Morte. Rio de Janeiro: Editora Fiocruz, 2006.

RUIZ, Erasmo. O Homem e a Morte: Uma poesia de Manuel Bandeira. 2009. Disponível em: http://www.redehumanizasus.net/ Acesso em: 01 de setembro de 2016. 
SANTOS, J. L. dos; CORRAL-MULATO, S.; BUENO, S. M. V. Morte e luto: a importância da educação para o profissional de saúde. Arq. Ciênc. Saúde UNIPAR, Umuarama, v. 18, n. 3, p. 199-203, set./dez. 2014

SIQUEIRA, Áurea E. Spricigo et. al. Teses Brasileiras sobre Luto - Um Estado da Arte. In: XVI Encontro da ABRAPSO Regional Sul. Disponível em: http: www.encontroregionalsul2016.abrapso.org.br

SIQUEIRA, Leonildo Campos. Protestantes Brasileiros diante da morte e do luto: observações sobre rituais mortuários. In: REVER. Ano 16. ํ⒊ Sep/Dez. 2016.

SOBRAL, Luciana O. da Gama. A morte como escola: a pedagogia de bem morrer na Cidade da Bahia (ca. 1640-1759). Faculdade de Filosofia e Ciências Humanas, Universidade Federal da Bahia, Salvador, 2014.203 f.:il. 